Case Report

\title{
A rare case of congenital diaphragmatic hernia in adult: an incidental finding during an elective procedure
}

\author{
Vinayagam Ganesan*, Venkatesh Sadayan Periyasamy, Gokila Mariappan
} Department of General Surgery, Sri Venkateswaraa Medical College and Research Centre, Pondicherry University,
Pondicherry, India

Received: 23 July 2020

Accepted: 05 September 2020

*Correspondence:

Dr. Vinayagam Ganesan,

E-mail: ganeshvinayag@gmail.com

Copyright: (c) the author(s), publisher and licensee Medip Academy. This is an open-access article distributed under the terms of the Creative Commons Attribution Non-Commercial License, which permits unrestricted non-commercial use, distribution, and reproduction in any medium, provided the original work is properly cited.

\begin{abstract}
Congenital diaphragmatic hernia consists of a defect of the diaphragm that allows the passage of abdominal viscera into the thorax. Congenital diaphragmatic hernia most commonly present in infancy and childhood due to respiratory distress. However, a few of them may escape into adulthood. A very few of these adult cases may be identified during a routine medical checkup for various other reasons without any cardio-respiratory problems. In our case report, we have diagnosed incidentally an asymptomatic left diaphragmatic hernia with cardio-mediastinal shifting in a 38 years old female admitted for left breast fibroadenoma excision during a routine pre-anesthetic check-up and underwent breast surgery without any cardio-respiratory problems.
\end{abstract}

Keywords: Congenital diaphragmatic hernia, Cardio-mediastinal shifting, Foramen of morgagni

\section{INTRODUCTION}

Congenital diaphragmatic hernia $(\mathrm{CDH})$ consists of a defect of the diaphragm that allows the passage of abdominal viscera into the thorax. There occurs a consequent displacement of the mediastinum to the contralateral side. It may be either Bochdalek's (posterolateral) type or morgagni's (sternocostal) type or paraesophageal hiatal hernia or eventration of the diaphragm. It occurs in <1-5:1000 live births and account for $8 \%$ of major congenital abnormalities. ${ }^{1}$ It is more common in left side $(76 \%)$ than right side $(20 \%)$ and rarely bilateral $(4 \%){ }^{2}$ Most cases $(63 \%)$ are isolated defects whereas the rest (37\%) are associated with other abnormalities. The risk is increased in advanced maternal age groups and decreased among blacks. ${ }^{3}$ It is more common in males (male/female ratio of 1.58$).{ }^{4}$ Congenital diaphragmatic hernia most commonly present in infancy and childhood either due to respiratory distress secondary to pulmonary hypoplasia and persistent pulmonary hypertension. ${ }^{5}$ However, a few of them may escape into adulthood as they become accustomed to living with certain difficulties and present late in life. ${ }^{6}$ A very few of these cases may be identified during a routine medical checkup for various other reasons. Typical changes including gas filled intestinal loops inside the thoracic cavity with a consequent push of mediastinal contents to contralateral side may be noticed. ${ }^{7}$ Here Computed tomography (CT) scan becomes the investigation of choice which shows fluid-filled intestinal loops in the chest which are dilated and contain several air-fluid levels.

\section{CASE REPORT}

A 39 years old female with three normal deliveries and regular breastfed admitted with the complaints of a lump in the left breast for 8 months, which was of insidious onset and gradually progressed to present size associated with on and off pricking type of pain. History of cyclical mastalgia was present. The patient was operated for a lump in the right breast four years back and post-operative period went uneventful during the first surgery. Now her complaints were of abdominal discomfort relieved on lying down position, bloating sensation, dysphagia- grade II 
(according to modified takita's grading). The patient was conscious, oriented, pulse rate $76 / \mathrm{min}$, blood pressure (BP) $120 / 70 \mathrm{mmHg}$, respiratory rate (RR)- 16 cycles per minute of abdomino-thoracic respiration. The Spo 2 was $100 \%$ in room air. Cardiovascular system- apex beat not appreciated, S1S2 heard over tricuspid, pulmonary and aortic areas, but not heard in mitral area. The respiratory system- decreased breast sounds over the left mammary region, abdomen soft and no tenderness, normal central nervous system examination. On examination left breast lump of size $2 \times 1.5 \mathrm{cms}$ approximately, firm in consistency, tender and mobile. There is also bilateral breast lumpiness. Clinically diagnosed as bilateral fibroadenosis breast with left breast fibroadenoma. Ultrasound breast was done reveals fibroadenosis both breast with well-defined oval shaped hypoechoic lesions noted in left breast parenchyma, probably benign (ACR BIRADS III). Fine needle aspiration cytology (FNAC) reported as fibroadenoma left breast lump, so planned for excision of the lump under general anaesthesia. Preoperative investigations were carried out. All routine blood and urine investigations were within normal limit. But chest X-ray showed left dome of the diaphragm was elevated and bowel loops shadows are visible on the left side of the chest pushes the heart into right side with mediastinal shifting and deviation of trachea towards the right side of the chest.

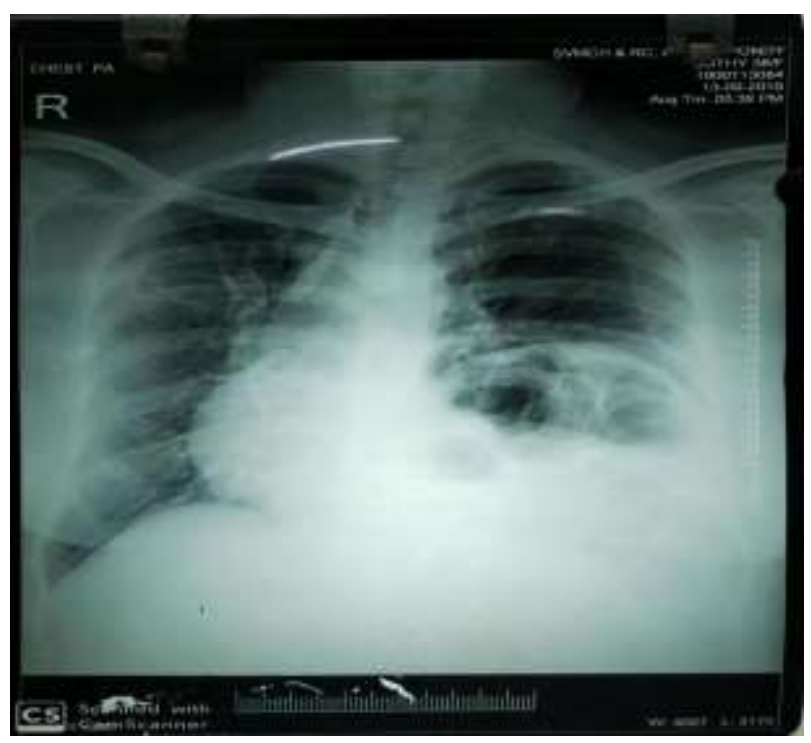

Figure 1: Chest X-Ray PA view showing herniation of bowel loops in left sided chest with cardio-mediastinal shifting.

Then planned to ultrasound abdomen, it shows bowel loops are abnormally higher on the left side, suggested CT abdomen to rule out the size of diaphragmatic hernia defect and the patient was advised for CT scan. Since the patient came for painful breast swelling, we decided to do breast surgery first. Echocardiography and pulmonary function test were normal. The patient was planned for breast surgery first explaining to her about the cardio-respiratory risk of general anaesthesia. After risk consent obtained, the patient was taken up for surgery. Intraoperative and postoperative period were uneventful. Surgical wound healed and the patient was discharged without any complication. The patient was convinced for diaphragmatic hernia repair in next sitting.

\section{DISCUSSION}

A congenital diaphragmatic hernia is herniation of abdominal viscera into the thorax through either a weakened area or a distinct defect in diaphragm due to pressure changes (decreased lung fluid pressure secondary to pulmonary hypoplasia or persistent pulmonary hypertension) or mechanical causes (early return of bowel into the peritoneal cavity from a physiological hernia) in thoraco-abdominal cavity whereas in adults, the most frequent cause of herniation seems to be trauma. Hernia through Foramen of Bochdalek is the most common type of congenital diaphragmatic hernia. It is usually posterolateral in location and more common on the left side. This is because the left opening of the posterior part of diaphragm closes later than its counterpart of the opposite side and also due to protective effect of the liver. They are usually big and the content is most commonly colon but may also contain small intestine, stomach and retroperitoneal structures such as a retroperitoneal pad of fat or left kidney. ${ }^{8}$ Incidental discoveries in adults are rare and when present are more common in females and on the right side (68\%). ${ }^{9}$ Hernia through Foramen of Morgagni is rare (2\% of Congenital diaphragmatic hernia (CDH)). They are more often anterior and are more common on the right side (90\%). They are usually small and carry a low risk of prolapse. The content is mostly omental fat but may also contain a transverse colon $(60 \%)$ or stomach $(12 \%) .{ }^{10}$ They carry a risk of hypoplasia of the right lobe of the liver.

Open surgery was done earlier wherein prosthetic patches or muscle flaps were used to close the defects but now thoracoscopic or laparoscopic approaches are being made. $^{11}$

A combination of investigations such as X-ray chest and abdomen, CT and magnetic resonance imaging (MRI) and upper GI double-contrast studies are useful in the identification of the viscera involved and planning a further line of management. X-ray reveals soft tissue opacity in lung base seen posteriorly on lateral views. ${ }^{12}$ Typical changes including gas filled dilated intestinal loops in the thoracic cavity having multiple air fluid levels with the consequent push of mediastinal contents to contralateral side may be noticed. But in most cases, especially in acute presentations where there is the incarceration of bowel loops, it is mostly misdiagnosed as pneumonia, pleural effusion, lung cyst, pneumothorax or atelectasis which can be avoided by careful analysis of continuity of bowel loops. pneumonia and pneumothorax can be ruled out by placing a feeding tube and filling it with contrast materials. ${ }^{13}$ 
CT scan with its coronal and sagittal reconstructions is the investigation of choice in any age group when there is clinical or radiological feature suggestive of $\mathrm{CDH}$. Typical findings in CT scan would be abutment of fat or soft tissue along the upper surface of the diaphragm, diaphragmatic discontinuity adjacent to the mass and continuous density above and below the diaphragm through the defect. All diaphragmatic hernias should be repaired at the time of diagnosis due to the risk of intestinal obstruction and strangulation they carry. Earlier they were repaired via laparotomy or thoracotomy. Now minimally invasive surgeries are also being done with the advantage of decreased pain, shorter hospitalization and improved cosmesis. When the defect is small, it is usually closed by interrupted non-absorbable suture. When the defect is large (exceeding 20-30 cm), the use of mesh is being recommended. ${ }^{14}$ Right sided defects are usually corrected by thoracoabdominal approach whereas for, the left side, the transthoracic or transperitoneal approach has been described.

All patients with $\mathrm{CDH}$ needs to undergo surgical correction to prevent any incarceration or obstruction or strangulation of intestinal loops in future. The outcome depends on the type of clinical presentation. Any delay in the diagnosis of $\mathrm{CDH}$ can result in significant morbidity and mortality at times in symptomatic adults but if they are expeditiously identified and repaired, their outcome is very good in contrast to those that present in neonates. ${ }^{15}$

\section{CONCLUSION}

The rare case of left-sided congenital diaphragmatic hernia with herniation of bowel loops in female adult and leads to cardio-mediastinal shifting diagnosed during a preoperative workup for elective fibroadenoma left breast excision. Since patient has asymptomatic diaphragmatic hernia with normal cardiorespiratory function and wants to get left breast fibroadenoma excision first. So, planned for breast surgery first and patient underwent left breast fibroadenoma excision under general anaesthesia without any complication during the intraoperative period. Postoperative period was also uneventful and the patient was discharged home and planned for elective laparoscopic diaphragmatic hernia repair later. Since most of the congenital diaphragmatic hernias in the adult are asymptomatic and left-sided $\mathrm{CDH}$ in females are very rare, diagnosis is made only during incidentally in preoperative workup other elective procedures. So always kept in mind that these kind of rare cases are difficult to diagnose in Outpatient department (OPD) basis, but when we have these $\mathrm{CDH}$ cases during another elective procedures, we should explain the cardiorespiratory complications during anaesthesia and should proceed for surgery, and then plan for diaphragmatic hernia repair later. But if cardiorespiratory functions are affected, then can delay the other elective procedure and should plan for diaphragmatic hernia first.
Funding: No funding sources

Conflict of interest: None declared

Ethical approval: Not required

\section{REFERENCES}

1. Bianchi E, Mancini P, De Vito, S. Congenital asymptomatic diaphragmatic hernias in adults: a case series. J Med Case Reports. 2013;7:125.

2. Prenatal detection and outcome of congenital diaphragmatic hernia: a French registry-based study - Gallot - 2007 - Ultrasound in Obstetrics \&amp; Gynecology - Wiley Online Library. Available at: https://obgyn.onlinelibrary.wiley.com/doi/full/10.10 02/uog.3863. Accessed on 10 July 2020.

3. Yang W, Carmichael SL, Harris JA, Shaw GM. Epidemiologic characteristics of congenital diaphragmatic hernia among 2.5 million California births, 1989-1997. Birth Defects Res Part A Clin Mol Teratol. 2006;76(3):170-4.

4. Torfs CP, Curry CJ, Bateson TF, Honoré LH. A population-based study of congenital diaphragmatic hernia. Teratology. 1992;46(6):555-65.

5. Congenital diaphragmatic hernia - ScienceDirect. [cited 2020 Jul 10]. Available from: https://www.sciencedirect.com/science/article/abs/pi i/S1055858610000144. Accessed on 10 July 2020.

6. A N, Z S, A M, S C. Delayed presentation of congenital diaphragmatic hernia. S Afr J Surg. 1997;35(2):74-6.

7. Gayer G, Bilik R, Vardi A. CT diagnosis of delayed presentation of congenital diaphragmatic hernia simulating massive pleuropneumonia. Eur Radiol. 1999;9(8):1672-4.

8. Stoll C, Alembik Y, Dott B, Roth M-P. Associated malformations in cases with congenital diaphragmatic hernia. Genet Couns. 2008;19(3):3319.

9. Bochdalek hernia. Radiology Reference Article | Radiopaedia.org. Available at: https://radiopaedia. org/articles/bochdalek-hernia. Accessed on $10 \mathrm{July}$ 2020.

10. Morgagni hernia. Radiology Reference Article | Radiopaedia.org. Available at: https://radiopaedia.org/articles/morgagni-hernia-2. Last accessed on 10 July 2020.

11. Nguyen TL, Le AD. Thoracoscopic repair for congenital diaphragmatic hernia: lessons from 45 cases. J Pediatr Surg. 2006;41(10):1713-5.

12. Gale ME. Bochdalek hernia: prevalence and CT characteristics. Radiology. 1985;156(2):449-52.

13. Sridhar AV, Nichani S. Late presenting congenital diaphragmatic hernia. Emerg Med J. 2004;21(2):2612.

14. Navakishore K, Sharma D, Gondu GR, Thumma VM, Gunturi SV, Reddy JM. Surgical Management of Adult Diaphragmatic Hernia - An Instituitional Experience. IJCMSR. Available at: https://www.ijcmsr.com/uploads/1/0/2/7/102704056 /ijcmsr_3_2_81_v2.pdf. Accessed on 3 June 2020. 
15. Baerg J, Kanthimathinathan V, Gollin G. Latepresenting congenital diaphragmatic hernia: diagnostic pitfalls and outcome. Hernia. 2012;16(4):461-6.
Cite this article as: Ganesan V, Periyasamy VS,

Mariappan G. A rare case of congenital diaphragmatic hernia in adult: an incidental finding during an elective procedure. Int Surg J 2020;7:351922 